\title{
Genetic Divergence in Indigenous Wild and Cultivated Rice Species of Manipur Valley
}

\author{
K. Medhabati, ${ }^{1}$ K. Rajiv Das, ${ }^{2}$ M. Rohinikumar, ${ }^{3}$ H. Sunitibala, ${ }^{1}$ and Th. Dikash Singh ${ }^{1}$ \\ ${ }^{1}$ Medicinal Plant and Horticulture Division, Institute of Bioresources and Sustainable Development, Takyelpat, Imphal 795001, India \\ ${ }^{2}$ Department of Environmental Biotechnology, Bharathidasan University, Tiruchirappalli 620024, India \\ ${ }^{3}$ Director of Research, Central Agricultural University, Iroisemba, Imphal 795004, India
}

Correspondence should be addressed to K. Medhabati; m_kangabam@yahoo.co.in

Received 25 August 2012; Accepted 19 September 2012

Academic Editors: J. Huang and D. Sun

Copyright (C) $2013 \mathrm{~K}$. Medhabati et al. This is an open access article distributed under the Creative Commons Attribution License, which permits unrestricted use, distribution, and reproduction in any medium, provided the original work is properly cited.

\begin{abstract}
Genetic divergence of 32 indigenous rice germplasms and five wild rice of which three from Manipur and two wild rice procured from IRRI, Philippines was investigated using Mahalanobis, $D^{2}$ statistic. Based on twelve agromorphological characters, the thirtyseven germplasms both wild and cultivated were grouped into five clusters based on the relative magnitudes of $D^{2}$ values following Tocher's method of cluster formation. Based on the rank totals, the characters which contributed maximum towards genetic divergence in the present studies were grain yield/plant, spikelet/panicle, 100 grain weight, grain length, days to $50 \%$ flowering, ear bearing tillers/plant, and flag leaf length. In the present study, maximum intercluster distance was estimated between cluster III and $\left(\sqrt{D^{2}}=14.09\right)$ which was closed followed by clusters II and $\mathrm{V}\left(\sqrt{D^{2}}=12.50\right)$. On the basis of their greater intercluster distance, high value of cluster mean according to the character to be improved and performance of the individual germplasms for the character, the germplasms could be used in hybridization programme for improvement of different plant characters in the rice germplasms of Manipur.
\end{abstract}

\section{Introduction}

Manipur valley which is also considered as rice bowl of the state has a large variability of indigenous rice cultivars that belong to Asian cultivated rice O. sativa $\mathrm{L}$. subspecies indica. So far, 44 indigenous rice cultivars along with two wild rice wainuchara one with perennial form and murshi another with annual weedy form have been recorded from Manipur valley by Singh and Sharma [1]. If one considers the percentage availability of indigenous rice cultivar per unit area Manipur valley has one land race of rice per $42 \mathrm{sq} \cdot \mathrm{km}$. According to traditional classification, more than 50 rice cultivars were cultivated in Manipur valley before the introduction of high-yielding varieties bred in Manipur. The high-yielding varieties of rice introduced from the plain or hill regions of the northern and southern parts of the country do not perform well in northeastern hill region [2]. The importance of local land races of rice in breeding programme lies in the evolution of gene complexes in the local cultivars that have coadapted to specific local environment through long period of natural selection. These gene complexes may not be readily reconstituted even by the modern recombinant DNA technology; we have to utilize the naturally occurring gene complexes for breeding of rice for specific local conditions.

The basic importance of genetic diversity in breeding for high yield has long been recognized as is evident from the results reported by several workers in different crops. The magnitude of heterosis in crop plants depends on the degree of genetic divergence between parental stocks and, consequently, may be used as an indicator of the inherent yielding capacity of a cross. While the importance of genetic diversity has long been appreciated by breeders, the basic difficulty has always been one of recognizing and estimating such diversity, shortness of actually making the cross. In view of the great importance of genetic diversity to breeding, techniques which can provide direct and reliable quantitative estimates of diversity at the genotypic level should prove to 
TABLE 1: Name of the genotypes included in the experiment.

\begin{tabular}{|c|c|c|c|}
\hline Sl. no. & Acc no. & Local name of the cultivars & Place of collection/parentage \\
\hline 1 & 31 & Chak-hao amubi & Thoubal district \\
\hline 2 & 32 & Chak-hao angouba & Imphal district \\
\hline 3 & 33 & Chak-hao poireiton & Imphal district \\
\hline 4 & 34 & Chak-hao sempak & Imphal district \\
\hline 5 & 40 & Champra phou & Imphal district \\
\hline 6 & 47 & Changlei & Thoubal district \\
\hline 7 & 70 & Heitup phou & Thoubal district \\
\hline 8 & 74 & Iroya & Thoubal district \\
\hline 9 & $74 \mathrm{~A}$ & Iroya A & Thoubal district \\
\hline 10 & 84 & Kakcheng phou & Bishenpur district \\
\hline 11 & 119 & Kumbi phou & Bishenpur district \\
\hline 12 & 123 & Laiphou & Thoubal district \\
\hline 13 & 129 & Langmanbi & Thoubal district \\
\hline 14 & 130 & Langphou & Bishenpur district \\
\hline 15 & 166 & Moirangphou & Bishenpur district \\
\hline 16 & 167 & Moirangphou khokngangbi & Bishenpur district \\
\hline 17 & $167 \mathrm{~A}$ & Moirangphou khokngangbi A & Bishenpur district \\
\hline 18 & 195 & Phoudum & Imphal district \\
\hline 19 & 196 & Phougak & Thoubal district \\
\hline 20 & 197 & Phoungang & Bishenpur district \\
\hline 21 & 198 & Phourel & Thoubal district \\
\hline 22 & 199 & Phourel akuppi & Thoubal district \\
\hline 23 & 200 & Phourel amubi & Thoubal district \\
\hline 24 & 201 & Phourel noining & Imphal district \\
\hline 25 & 202 & Phourel phoudongba & Imphal district \\
\hline 26 & 203 & Phourel phoujao & Thoubal District \\
\hline 27 & 204 & Phourel tujombi & Thoubal district \\
\hline 28 & 218 & Sangsangba & Imphal district \\
\hline 29 & 236 & Taothabi & Bishenpur district \\
\hline 30 & 237 & Taothabi angouba & Bishenpur district \\
\hline 31 & 255 & Tumai angouba & Imphal district \\
\hline 32 & 263 & Phourel yenthik & Bishenpur district \\
\hline \multicolumn{4}{|c|}{ Name of the wild cultivars } \\
\hline 33 & 1 & O. rufipogon local cultivar 1 wainuchara & Bishenpur district \\
\hline 34 & 2 & O. rufipogon local cultivar 2 wainuchara manbi & Bishenpur district \\
\hline 35 & 3 & O. rufipogon local cultivar 3 murshi & Imphal district \\
\hline 36 & 4 & Oryza rufipogon & IRRI, Philippines \\
\hline 37 & 5 & Oryza nivara & IRRI, Philippines \\
\hline
\end{tabular}

be valuable. In crop improvement programme, the importance of genetic diversity existing in the material has been emphasized by several workers $[3,4]$. The more diverse the parents, the more are the chances of increased spectrum of variability. Systematic evaluations of local rice germplasms of both $O$. sativa cultivars and wild species for morphological and agronomic characters and genetic diversity are urgently needed as far as the improvement of the local germplasms are contemplated. Such a study should also allow critical evaluation of the adaptive radiation of rice cultivars, for crop plants evolved from wild species in the areas showing great genetic diversity followed by a ramification of an adaptive type in a series of new adaptive zones [5]. The wealth of Manipur in terms of local rice germplasms is threatened by the rapid spread of newly developed improved rice varieties. Old and obscure rice varieties are being rapidly replaced by new ones in many areas. Primitive and wild forms are being wiped out by land clearing associated with irrigation and drainage projects, housing and urbanization, and so forth. For several decades, it was taken for granted that diverse rice germplasms were readily available in the native habitats of the crop. However, the gradual and widespread disappearance of the diverse and less productive indigenous land races by replacement with improved cultivars went on unnoticed. It is 
TABle 2: Average intra- and inter-cluster $D$ and $D^{2}$ values of 37 rice cultivars of Manipur Valley.

\begin{tabular}{lccccc}
\hline & I & II & III & IV & V \\
\hline I & 35.80 & 63.89 & 114.69 & 55.13 & 109.69 \\
& $(5.98)$ & $(9.99)$ & $(10.71)$ & $(7.42)$ & $(10.47)$ \\
& & 34.18 & 198.44 & 90.65 & 156.32 \\
II & & $(5.35)$ & $(14.09)$ & $(9.52)$ & $(12.50)$ \\
& & & 36.15 & 70.70 & 44.78 \\
III & & & $(6.01)$ & $(8.41)$ & $(6.69)$ \\
& & & & 0.0 & 54.27 \\
IV & & & & & $(7.37)$ \\
& & & & & 0.0 \\
V & & & & & \\
\hline
\end{tabular}

in this context that scientists, particularly the plant breeders of the state started giving their thought with all seriousness for the conservation of local rice germplasms. Thus, it is extremely important to study the genetic composition of the germplasms of existing modern day cultivars in comparison with their ancestors and related species. This will not only provide information on their phylogenetic relationship but also will indicate a chance of finding new and useful genes, as the accessions with most distinct DNA profiles are likely to contain a greater number of novel alleles.

The use of Mahalanobis $D^{2}$ statistics for estimating genetic divergence had been emphasized by many workers [4-7] because it permitted precise comparison among all possible pairs of population in any group before affecting actual crosses. In addition to aiding in the selection of divergent parents for hybridization, $D^{2}$ statistics measures the degree of diversification and determines the relative contribution of each component character to the total divergence [8]. The utility of multivariate analysis in quantifying the degree of divergence between populations to understand the trend of evolutionary pattern, to assess the relative contribution of different components to the total divergence and to determine the nature of forces operating on inter- and intracluster levels has greatly been emphasized [9-12]. Further, such studies have also permitted the choice of genetically divergent parents to obtain desirable recombinants in segregating generations [13].

\section{Materials and Methods}

The experimental material consisted of 35 indigenous rice germplasms of Manipur valley, namely, Thoubal district with 15 germplasms, Imphal district with 10 germplasms and Bishenpur district with 10 germplasms, and 2 wild rice $O$. rufipogon and $O$. nivara procured from IRRI, Philippines, 3 wild rice from Manipur valley, namely, O. rufipogon local cultivars namely wainuchara, wainuchara manbi, and murshi. Accession numbers and local names of the germplasms are given in Table 1.

These germplasms were grown in the experimental farm of Manipur University, Manipur, India during kharif season of 2009 and 2010. The experiment was laid out in the research field of the University in the randomized block design with three replications. The interrow spacing was maintained at $20 \mathrm{~cm}$. The recommended plant protection measures and agronomical practices were followed. The experimental data on various quantitative and qualitative characters were recorded as per criteria laid down in the standard Evaluation System for rice IRTP and "Descriptors for Rice" published jointly by International Rice Research Institute and International Board for plant Genetic Resources [14]. Ten plants from middle three rows of each plot were randomly sampled and the quantitative characters were recorded following actual measurement on each of the sampled plants and then averaged it out. The qualitative traits were recorded through visual observation only. Nine qualitative traits were taken for the study. They are leaf blade colour, leaf blade pubescence, basal leaf sheath colour, leaf angle, ligule colour, collar colour, auricle colour, flag leaf angle, and ligule shape. The variables measured for quantitative characters were flag leaf length, flag leaf width, ligule length, culm diameter, panicle length, culm length, ear bearing tillers/plant, days to $50 \%$ flowering, grain length, 100 grain weight, spikelet/panicle, and grain yield/plant. The two-year data were pooled in the analysis. Mahalanobis $D^{2}$ statistics was used to estimate genetic divergence among the thirty-seven germplasms. The germplasms were grouped into clusters according to Tocher's methods by Rao [15].

\section{Results and Discussion}

The thirty-seven rice germplasms both wild and cultivated were grouped into five clusters based on the relative magnitude of $D^{2}$ values following the Tocher's method of cluster formation [15] with the criterion that the intracluster average $D^{2}$ values should be less than the intercluster $D^{2}$ values (Table 2). Maximum cultivars were in cluster I involving 25 out of 37 germplasms (Table 3). However, clusters IV and V had only one cultivar each. Average inter- and intra-cluster distances are presented in cluster diagram (Figure 1) and are also presented as a supplement of the table using $D=D^{2}$ values of average inter- and intra-cluster. This depicted the genetic diversity in an easily understandable manner and provided information about relationships of different clusters. But the diagram presented was not exactly to the scale. The value of intracluster distance ranged from 0.00 (clusters IV and V) to 5.98 (cluster 1). It could be indicated that clusters I and III were highly divergent from clusters II, IV, and V. Moreover, cluster IV appeared less divergent from cluster II and cluster $\mathrm{V}$ to cluster III based on the values of intracluster distances. The average intercluster distance varied from 44.78 (clusters $\mathrm{V}$ and II) to 198.44 (clusters III and II). From the intercluster distances, it could be inferred that the cultivars belonging to clusters III and II (198.44) and clusters V and II (156.32) were more divergent and had a wide genetic variation than the others.

Clustering of thirty-seven germplasms with twenty-five germplasms into cluster I, six germplasms in cluster II, four germplasms in cluster III, and one germplasms each 
TABLE 3: Grouping of 37 rice cultivars into 5 clusters.

\begin{tabular}{|c|c|c|}
\hline Cluster & $\begin{array}{l}\text { No. of cultivars } \\
\text { included }\end{array}$ & Name of cultivar with entry no. \\
\hline I & 25 & $\begin{array}{l}\text { Chak-hao angouba (32), Chak-hao poireiton (33), Chakhao-sempak (34), Heitup phou } \\
\text { (70), Iroya (74), Kakcheng phou (84), Langmanbi (129), Moirangphou khokngangbi } \\
\text { (167), Phourel phoudongba (202), Phourel phoujao (203), Changlei (47), Kumbi-phou } \\
\text { (119), Laiphou (123), Sangsangba (218), Taothabi (236), Langphou (130), Moirangphou } \\
\text { (166), Chak-hao amubi (31), Champra phou (40), Phoudum (195), Phourel yenthik } \\
\text { (263), Tumai angouba (255), Phourel tujombi (204), Moirangphou khokngangbi (A), and } \\
\text { Phougak (196) }\end{array}$ \\
\hline II & 6 & $\begin{array}{l}\text { Iroya A (74A), Phoungang (197), Phouren (198), Phourel akupi (199), Phouren amubi } \\
\text { (200), and Phouren noining (201) }\end{array}$ \\
\hline III & 4 & $\begin{array}{l}\text { Oryza wainuchara, syn. O. rufipogon, local collection } 11 \text { (1), Oryza wainucharamanbi, } \\
\text { syn. O. rufipogon local collection } 111 \text { (2), Oryza murshi, syn. O. rufipogon, local } \\
\text { collection } 1 \text { (3), and Oryza rufipogon (4) }\end{array}$ \\
\hline IV & 1 & Taothabi angouba (237) \\
\hline $\mathrm{V}$ & 1 & O. nivara (5) \\
\hline
\end{tabular}

TABLE 4: Diversity in 12 agronomic characters of 37 rice germplasms.

\begin{tabular}{|c|c|c|c|}
\hline S. no. & Characters & Minimum & Maximum \\
\hline 1 & Flag leaf length & $\begin{array}{l}19.44 \text { O. rufipogon local cultivar } \\
\text { (2) wainuchara manbi }\end{array}$ & 51.19 Phourel amubi (200) \\
\hline 2 & Flag leaf width & $\begin{array}{l}0.97 \text { O. rufipogon local cultivar (3) } \\
\text { murshi }\end{array}$ & 1.84 Champra phou (40) \\
\hline 3 & Ligule length & 1.22 Chak-hao poireiton (33) & 3.06 Chak-hao poireiton (33) \\
\hline 4 & Culm diameter & 0.60 Langphou (130) & 1.42 Phourel (198) \\
\hline 5 & Panicle length & 19.42 Chak-hao amubi (31) & 27.56 Heitup phou (70) \\
\hline 6 & Culm length & $\begin{array}{l}73.87 \text { O. rufipogon local cultivar } \\
\text { (1) wainuchara }\end{array}$ & 159.00 Phougak (196) \\
\hline 7 & Ear bearing tillers/plant & $\begin{array}{l}\text { 5.50 O. rufipogon local cultivar (1) } \\
\text { wainuchara }\end{array}$ & 13.67 Phourel akupi (199) \\
\hline 8 & Days to $50 \%$ flowering & 87.33 Phoudum (195) & 121.17 Phourel (198) \\
\hline 9 & Grain length & 0.77 Phoudum (195) & 2.36 Chak-hao poireiton (33) \\
\hline 10 & 100 grain weight & 1.85 Oryza rufipogon (4) & 3.80 Chak-hao poireiton (33) \\
\hline 11 & Spikelet number/panicle & 56.67 Oryza rufipogon (4) & 151.73 Phoungang (197) \\
\hline 12 & Grain yield/plant & $\begin{array}{l}\text { 5.22 O. rufipogon Local cultivar (3) } \\
\text { murshi }\end{array}$ & 44.95 Phourel (198) \\
\hline
\end{tabular}

in clusters IV and $\mathrm{V}$, each indicated presence of genetic diversity among the germplasms (Table 3 ). The random clustering pattern of germplasms from different valley districts of Manipur indicated that the genetic diversity of the germplasms is not necessarily related with the distribution of germplasms in different districts of Manipur valley. The genetic diversity among the germplasms in the present study may be resulted from genetic drift and selection that cause greater diversity than geographical distribution of Manipur valley as suggested by Murty and Arunachalan [4]. Taothabi angouba (30) and Oryza nivara (37) maintained their separate identities by making monogenetic groups, that is, clusters IV and V while forming clusters. It might be due to its different genetic makeup from that of the other germplasms.
3.1. Average Inter- and Intra-Cluster Distances. Maximum intercluster distance suggested wider diversity between the groups; while minimum intercluster distance indicated closer relationship by Singh et al. [16]. Higher intracluster distance also indicated greater heterogeneity of the cultivars by Pattnaik [17]. Genotypes belonging to different clusters separated by high estimated statistical distance could be used in hybridization programme for obtaining a wide spectrum of variation among the segregants [18]. Further, the magnitude of heterosis largely depends upon the degree of genetic diversity in the parental lines Roy and Panwar [19].

In the present study, maximum intercluster distance was estimated between cluster III $\left(\sqrt{D^{2}}=14.09\right)$, which was closely followed by cluster II, and V $\left(\sqrt{D^{2}}=12.50\right)$. It is suggested that the crossing between the selected germplasms 
TABLE 5: Relative contributions of individual character towards divergence calculated under different methods.

\begin{tabular}{|c|c|c|c|}
\hline Sl. no. & Characters & Rank total & Percentage to rank total \\
\hline 1 & Flag leaf length & 1763 & 3.40 \\
\hline 2 & Flag leaf & 3586 & 6.90 \\
\hline 3 & Ligule length & 6841 & 13.17 \\
\hline 4 & Culm diameter & 18093 & 34.82 \\
\hline 5 & Panicle length & 6321 & 12.17 \\
\hline 6 & Culm length & 4954 & 9.54 \\
\hline 7 & Ear bearing tillers/plant & 1961 & 3.77 \\
\hline 8 & Days to $50 \%$ flowering & 2831 & 5.45 \\
\hline 9 & Grain length & 2465 & 4.7 \\
\hline 10 & 100 grain weight & 1031 & 1.98 \\
\hline
\end{tabular}

NB: In this method, the smallest contribution to the percentage rank total will be the highest contribution towards divergence. It is just opposite to other methods. This means that if the rank total increases, the percentage of contribution towards divergence decreases.

from clusters II and III or clusters II and V will give rise to high heterotic crosses and a wide spectrum of variation among the segregants. Since cluster 1 consisted of 25 germplasms with appreciably high value of intracluster distances, presence of high heterogeneity among the germplasms is expected. Hence, subclustering of cluster 1 is an approach towards the effective selection of desired parents for hybridisation programme within the cluster. The maximum inter-sub-clusters III and V which was closely followed by subclusters VIII and IX.

3.2. Diversity in 12 Agronomic Characters. Diversity in 12 agronomic characters of rice germplasms was shown in Table 4. Considerable genetic diversity is observed in almost all the characters of the cultivars under study.

3.3. $D^{2}$ Analysis. The calculated values of $D^{2}$ were tested against the tabulated values of $X^{2}$ at $5 \%$ level of significance for 12 degrees of freedom being much lower than minimum calculated values of $D^{2}$ which obviously shows that $D^{2}$ values were significant.

3.4. Contribution of Each Germplasm towards Divergence. The relative contribution of each germplasm towards divergence is presented in Table 5. It was revealed from the table that germplasm O. rufipogon had an average maximum value of divergence $\left(D^{2}=138.81\right)$ closely followed by Oryza murshi $\left(D^{2}=123.65\right)$, wainuchara manbi $\left(D^{2}=122.27\right)$, O. nivara $\left(D^{2}=108.21\right)$, Phouren $\left(D^{2}=102.16\right)$, and O. rufipogon local cultivar 1 wainuchara $\left(D^{2}=90.95\right)$ and in divergence $\left(D^{2}=138.81\right)$ closely followed by $O$. rufipogon local cultivar 3 murshi $\left(D^{2}=123.65\right)$, O. rufipogon local cultivar 2 wainuchara manbi $\left(D^{2}=122.27\right), O$. nivara $\left(D^{2}=108.21\right)$, Phouren $\left(D^{2}=102.16\right)$, and $O$. rufipogon local cultivar 1 wainuchara $\left(D^{2}=90.95\right)$ and in turn contributed 5.76\%, 5.13\%, 5.07\%, 4.51\%, 4.24\%, 3.77\%, respectively, towards total divergence. On the other hand,

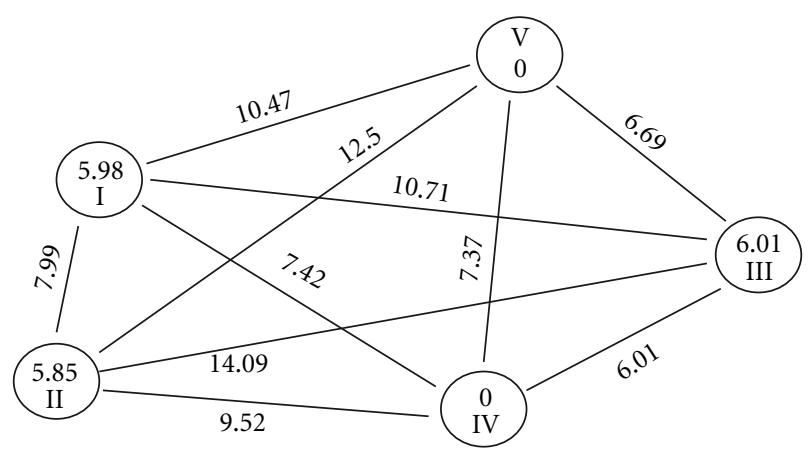

FIgURE 1: Cluster diagram with inter- and intra-cluster distance $\left(D^{2}\right)$.

germplasm Laiphou had minimum average divergence $\left(D^{2}=\right.$ 48.21) which contributed only $1.20 \%$ towards divergence and followed by Changlei $\left(D^{2}=41.72\right)$, Phourel phoujao $\left(D^{2}=41.82\right)$, and Kumbi phou $\left(D^{2}=42.82\right)$ contributing $1.73 \%, 1.73 \%$, and $1.78 \%$, respectively, towards divergence. It may, further, be pointed out that the remaining germplasms had an average $D^{2}$ value ranging from 43.31 to 102.16 and contributed only from $1.80 \%$ to $4.24 \%$ towards divergence.

The present findings indicated that, maximum intercluster distance was estimated between cluster III $\left(\sqrt{D^{2}}=14.09\right)$ which was closely followed by clusters II and $\mathrm{V}\left(\sqrt{D^{2}}=\right.$ 12.50). It is s suggested that the crossing between the selected germplasms from clusters II and III or clusters II and V will give rise to high heterotic crosses and a wide spectrum of variation among the segregants. However, hybridization programme between the germplasms of cluster I, if considered necessary, crossing between the selected germplasms from the subcluster III and V or VIII and VII or III and VIII or III and VI is expected to give the satisfactory result.

The salient findings obtained from the present studies and their possible implications in the genetic improvement of indigenous and wild rice germplasms of Manipur are summarised hereunder. In the studies for genetic divergence of 37 rice germplasms, significance of $D^{2}$ values revealed the presence of considerable divergence among the genotypes. Based on the rank totals, the characters which contributed maximum towards genetic divergence in the present studies were grain yield/plant, spikelets/panicle, 100 grain weight, grain length, days to $50 \%$ flowering, ear bearing tillers/plant, and flag leaf length. Clusters with the highest mean values of agronomic characters and best-performing germplasms within the cluster were identified. Best performers for hybridisation were shown in Table 6.

\section{Conclusion}

Rice being the staple food crop of the people of Manipur, rice culture itself was associated with the history and culture of Manipur. As the state of Manipur is located in the IndoChina region, which is considered to be the primary centre of origin of rice, diverse forms of indigenous rice cultivars or land races including the wild forms are expected. The 
TABLE 6: Best performers for hybridization.

\begin{tabular}{lcc}
\hline Sl. no. & Germplasms & Characters \\
\hline 1 & Phourel amubi & Flag leaf length \\
2 & Chak-hao Poireiton and Champra phou & Flag leaf width \\
3 & Phouren & Ligule length, days to 50\% flowering, and grain yield/plant \\
4 & Chak-hao poireiton & Culm diameter, grain length, and 100 grain weight \\
5 & Heitup phou & Panicle length \\
6 & Phougak & Culm length \\
7 & Phouren akuppi & Ear bearing tillers/plant \\
8 & Phoungang & Spikelet number/plant \\
\hline
\end{tabular}

expectations of the presence of wild rice and diverse forms of wild rice O. rufipogon local cultivar 1 "wainuchara" and annual weedy rice O. rufipogon local cultivar 3 "murshi" and one land race per $42 \mathrm{sq} \cdot \mathrm{km}$ area of Manipur valley. The future scope of the present investigation is to go further into the research and development work for improvement of indigenous rice germplasms of Manipur valley. Based on the present findings, breeding for various objectives in the indigenous rice cultivars of Manipur valley to be continued. Gene actions for various quantitative traits in the selected parents are to be investigated in order to adopt appropriate breeding techniques for production breeding programmes of local rice germplasms of Manipur. The above observations open up a new vista to the rice researchers of Manipur to obtain a firsthand information regarding variability of rice germplasms and also to trace the phylogenetic relationship between the indigenous rice varieties and their wild progenitors through $D^{2}$ analysis.

\section{Conflict of Interests}

The authors declare that they have no conflict of interests.

\section{References}

[1] Singh and Sharma, Collection, characterization and evaluation of rice germplasm of Manipur [Ph.D. thesis], Manipur University, Manipur, India, 1998.

[2] A. V. Asthana and N. D. Majumdar, "Studies in rice germplasms of North Eastern Hill Region," Research Bulletin, no. 11, 1981.

[3] A. B. Joshi and N. L. Dhawan, "Genetic improvement of yield with special reference to self- fertilizing crops," Indian Journal of Genetics and Plant Breeding, vol. 26, pp. 101-113, 1966.

[4] Murty and V. Arunachalan, "The nature of genetic divergence in relation to breeding system in crop plants," Indian Journal of Genetics and Plant Breeding A, vol. 26, pp. 188-198, 1966.

[5] N. I. Vavilov, The Origin, Variation, Immunity and Breeding of Cultivated Plants, vol. 13 of Translated by K. Stars Chester, Chronica Britanica, Washington, DC, USA, 1951.

[6] R. B. Singh and S. S. Bains, "Genetic divergence for giving out turn and its components in upland cotton G.hirsutum L," Indian Journal of Genetics and Plant Breeding, vol. 28, pp. 262-268, 1968.

[7] R. N. Singh and M. P. Gupta, "Multivariate analysis of divergence in upland cotton," Indian Journal of Genetics and Plant Breeding, vol. 47, pp. 11-14, 1968.
[8] B. D. Singh, Principles and Methods of Plant Breeding, Kalyani Publishers, New Delhi, India, 4th edition, 1990.

[9] C. D. Michener and R. R. Sokal, "Aquantitative approach to a problem in classification," Evolution, vol. 11, pp. 130-162, 1957.

[10] R. R. Sokal, "Quantification of systematic relationship and polygenic trends," in Proceedings of the 10th International Congress of Entomology, vol. 1, pp. 409-416, 1959.

[11] H. Morishima and H. I. Oka, "The patterns of interspecific variation in the genus Oryzaits quantitative representation by statistical methods," Evolution, vol. 14, pp. 153-165, 1960.

[12] B. R. Murty and M. I. Qadri, "Analysis of divergence in some self compatible forms of Brassica compestris var.brown sarson," Indian Journal of Genetics and Plant Breeding, vol. 26, pp. 45-58, 1966.

[13] J. Ram and D. V. S. Panwar, "Interspecific divergence in rice," Indian Journal of Genetics and Plant Breeding, vol. 30, pp. 1-10, 1970.

[14] IBPGR and IRRI publication, Descriptors for Rice (Oryza sativa L.), IBPGR and IRRI publication, Metro Manila, Philippines, 1980.

[15] C. R. Rao, Advanced Statistical Methods in Biometrical Research, John Wiley and Sons, New York, NY, USA, 1952.

[16] S. K. Singh, R. S. Singh, D. M. Maurya, and O. P. Verma, "Genetic divergence among lowland rice cultivars," Indian Journal of Genetics and Plant Breeding, vol. 47, pp. 11-14, 1987.

[17] L. K. Pattnaik, Genetic variability and character association in low-land rice cultures [M.S. thesis], Orissa University of Agriculture and Technology, Odisha, India, 1992.

[18] R. N. De Reddy, J. N. Surya, A. V. Rao, and K. K. Mohanty, "Genetic divergence in early rice under two situations," Indian Journal of Genetics, vol. 52, pp. 225-229, 1992.

[19] A. Roy and D. V. S. Panwar, "Genetic divergence in some rice (O.sativa L) genotypes," Annals of Agricultural Research, vol. 14, pp. 276-281, 1993. 

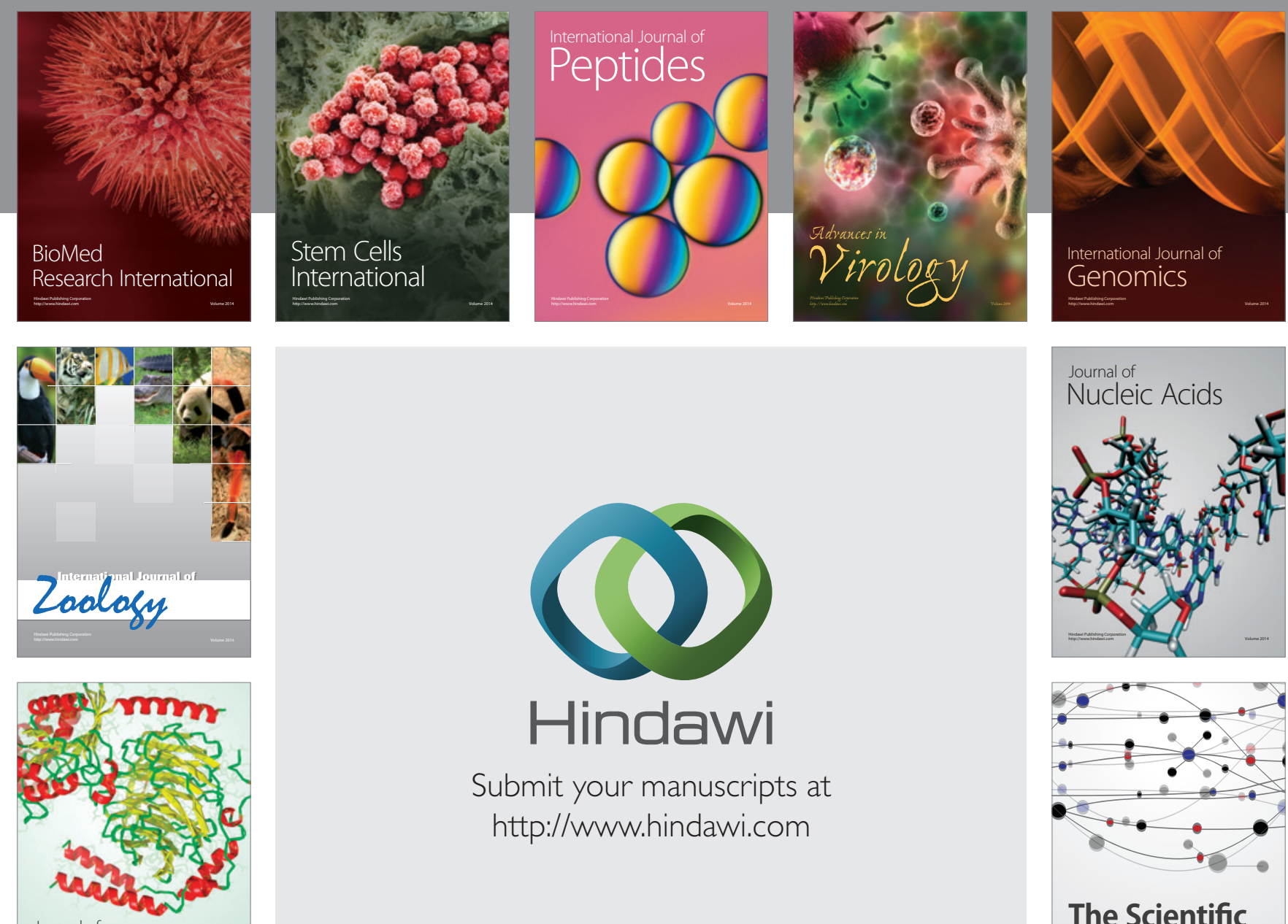

Submit your manuscripts at

http://www.hindawi.com

Journal of
Signal Transduction
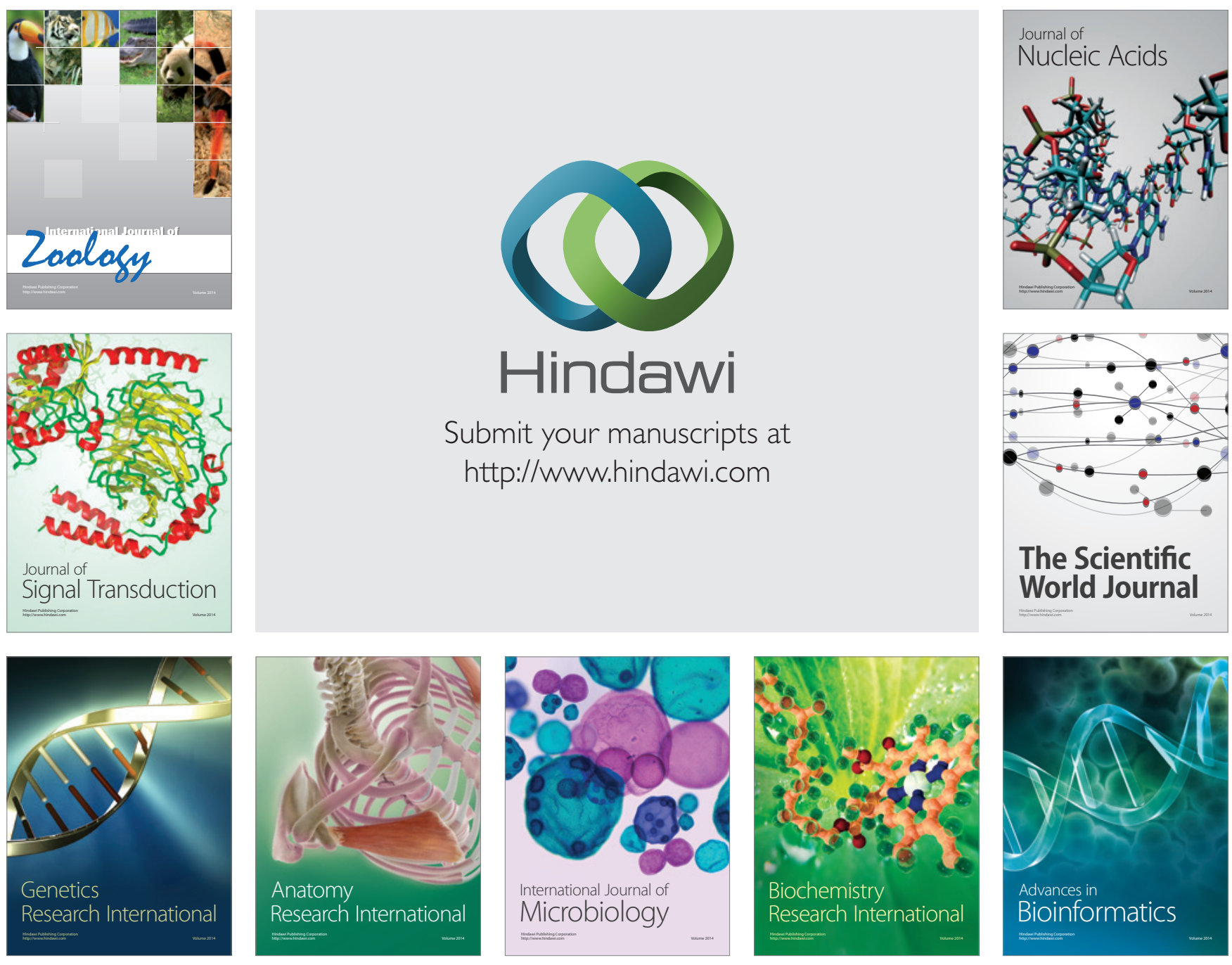

The Scientific World Journal
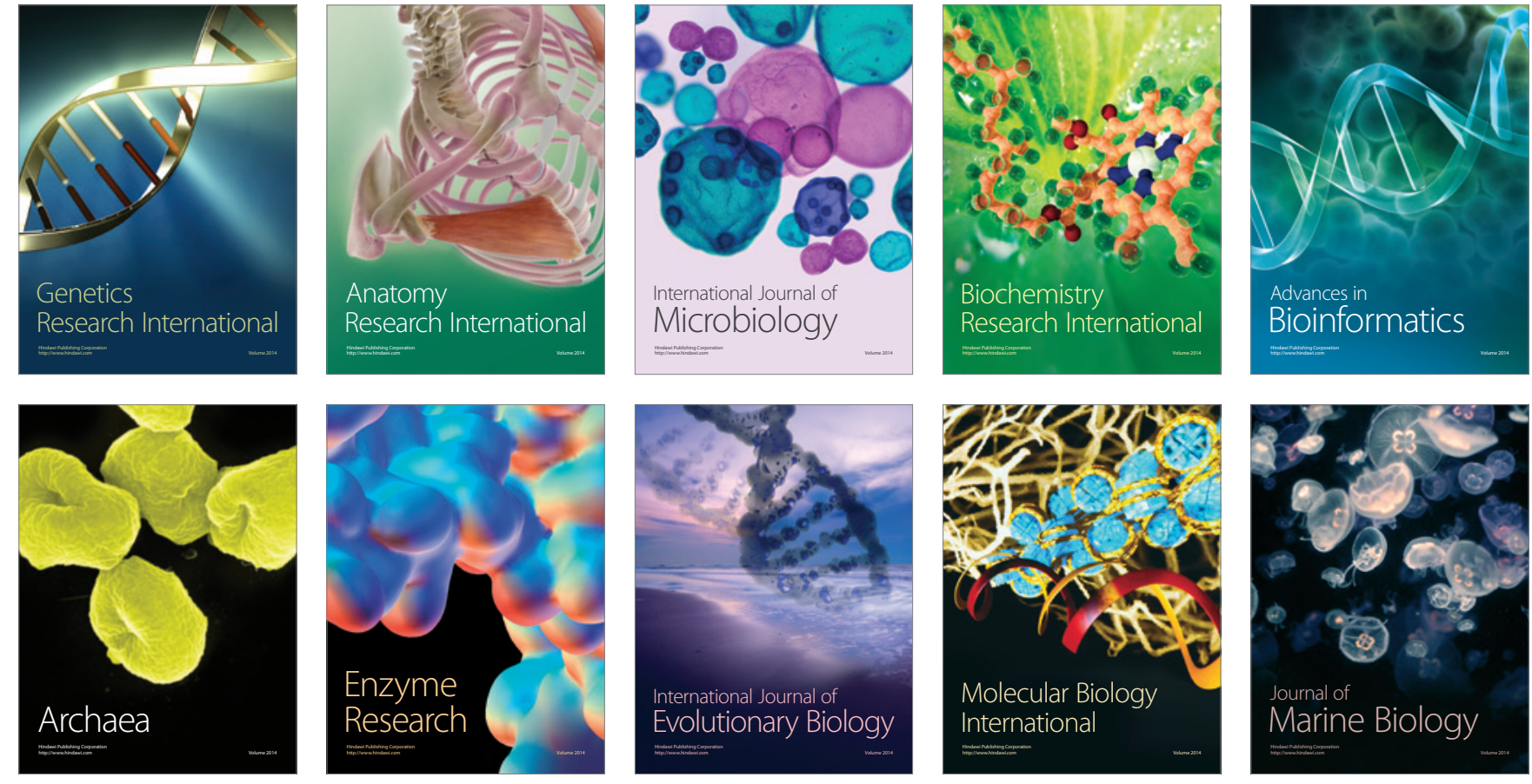